\title{
EDITORIAL
}

\section{Memoria(s) en el cine, memoria(s) del cine}

\author{
Irene Cambra Badii*
}

\author{
Universidad de Buenos Aires-CONICET
}

Hoy sólo tienes

la fiel memoria y los desiertos días. Nadie pierde (repites vanamente) sino lo que no tiene y no ha tenido nunca, pero no basta ser valiente para aprender el arte del olvido.

Jorge Luis Borges, 1964 (fragmento)

Desde la segunda mitad del siglo XX vivimos en una "era de la conmemoración". En este "clima de época memorialista”, como ha sido llamado por Andreas Huyssen, proliferan actos de homenaje y lugares de memoria (lieux de mémoire, noción acuñada por el historiador francés Pierre Nora) a partir de la necesidad de crear archivos y organizar celebraciones en torno a hechos que nuclean los recuerdos sociales, ya sean gratos o traumáticos. Así, distintos edificios, sitios, fechas, objetos, personas, libros, consignas, que tienen un alto valor simbólico para una comunidad, se convierten en lugares destacados donde se produce memoria en acto, donde se cristalizan distintos sentidos acerca del pasado, y se enmarcan las expectativas del porvenir.

¿Puede entonces el cine ser un lugar de memoria? En tanto productor de memoria, podríamos decir que sí. ¿Pero en qué condiciones el cine reproduce memorias ya compartidas, y en qué condiciones crea nuevas formas de representación? ¿En qué sentido acuña una memoria colectiva, producto de determinado grupo y contexto socio-histórico, y en qué sentido evidencia un recuerdo personal e íntimo?

Muchas veces, el cine se propone de manera explícita llevar a la pantalla determinadas formas de recordar el pasado, y otras veces, esto se puede leer entre líneas, con una mirada suplementaria que sorprenda incluso al realizador de la obra en relación a los efectos producidos. En ambos casos, es una extraordinaria experiencia de pensamiento y acción, que permite analizar la memoria colectiva y las formas de producción de recuerdos personales y sociales.

Como sabemos, los estudios sobre Memoria incluyen una amplia y variada gama de conceptos, discursos y teorías. Frecuentemente, se considera a la memoria en tanto polo distinguido de otro concepto: historia y memoria, memoria y olvido, memoria y recuerdo, memoria social y memoria individual. Tradicionalmente, el término memoria alude a la capacidad de almacenamiento de ideas o sucesos previos. Sin embargo, tal como señala Eduardo Laso, ya desde su primer modelo de aparato psíquico Freud distinguía las huellas mnémicas de la evocación de un suceso del pasado en la consciencia. Esta diferencia entre memoria y recuerdo se mantuvo a lo largo de toda su obra, y nos permite adentrarnos a su vez en la diferenciación entre memoria e inconsciente, que conserva aquello que el Yo rechaza.

Así, recordamos cosas que no podrían ser recordadas porque no ocurrieron (los falsos recuerdos) y no recordamos hechos que nos acontecieron. Sucesos insignificantes de nuestro pasado persisten en nuestro recuerdo, y caen en el olvido acontecimientos que por su significatividad marcaron nuestra vida. Todo recuerdo es en última instancia "encubridor" y está atravesado por motivaciones inconscientes que operan sobre las huellas mnémicas, determinando tanto lo que se olvida y lo que se recuerda, como el modo en que nuestra memoria acude a la consciencia luego de ser afectados los hechos pasados por distorsiones, transacciones e infidelidades. Olvido y recuerdo están

* irenecambrabadii@gmail.com 
inconscientemente motivados y tienen un destinatario: se recuerda para alguien que ocupe el lugar del Otro. De ahí que en los recuerdos el sujeto -y también una sociedad-al mismo tiempo se reconoce y se desconoce (Laso, 2016).

Fue Maurice Halbwachs quien propuso una concepción holística, sociológica, acerca de la memoria, que articula el proceso personal con el social. En 1925, en su reconocida obra Los marcos sociales de la memoria, definió la memoria colectiva como la memoria de los miembros de un grupo que reconstruyen el pasado a partir de sus intereses y del marco de referencias presentes. Esta memoria colectiva asegura la identidad, la naturaleza y el valor del grupo. Para Halbwachs no hay memoria universal, común a todos los sujetos (como podría pensarse la fidelidad a una supuesta verdad histórica unificada), sino memorias colectivas sostenidas por grupos en determinados tiempos y espacios. Esto hace que coexistan memorias parciales e incluso antagónicas, que libran "batallas por la memoria”, para usar la expresión de Elizabeth Jelin. Éstas son contiendas sobre el sentido del pasado en las que se enfrentan múltiples actores sociopolíticos que van estructurando distintos relatos del pasado. La memoria se vuelve un proceso abierto y pasible de ser reinterpretado constantemente, está sujeta a cambios, transformaciones y fracturas acordes a los cambios políticos y culturales o a la modificación de la sensibilidad social en momentos específicos.

La memoria, pues, es vista en su carácter transitorio, cambiante, moldeable. Se distancia cada vez más de las ideas de memoria como un archivo, es decir, posible de completarse algún día, y de la representación exacta de los sucesos del pasado.

La memoria -personal y social- está inscripta en huellas que testimonian del pasado. Y es la historia la encargada de volver esas huellas un discurso. Cómo se leen las huellas hace al campo de las diversas interpretaciones del sentido del pasado, las que no escapan a la trama de los deseos, ideales y fantasmas inconscientes -sean del sujeto o de una comunidad-. (Laso, 2016)

Más allá del recuerdo de pasados traumáticos a través del cine (ampliamente estudiado desde la Sociología, la Antropología, el Psicoanálisis, la Psicología, en particular en relación con la Shoah y con el terrorismo de Estado en el contexto argentino), en este número del Journal Ética y Cine-que tengo el privilegio de organizar como Editora invitada- se propone una lectura transversal sobre la(s) memoria(s), analizando diversos filmes en función de la construcción personal y social de los recuerdos.

En Rashômon. La memoria y su conexión con el pasa- do, Marina Trakas recorre las distintas versiones sobre la muerte del samurái en el reconocido film de Akira Kurosawa, para analizar el escepticismo y el relativismo respecto de la verdad y la memoria. No podemos acceder al pasado "tal cual como sucedió”, y nos queda ver entonces qué hacemos con ello, cómo recordarlo y cómo transmitirlo. El fotograma de tapa de este número del Journal rinde homenaje a esa obra cumbre del cine japonés.

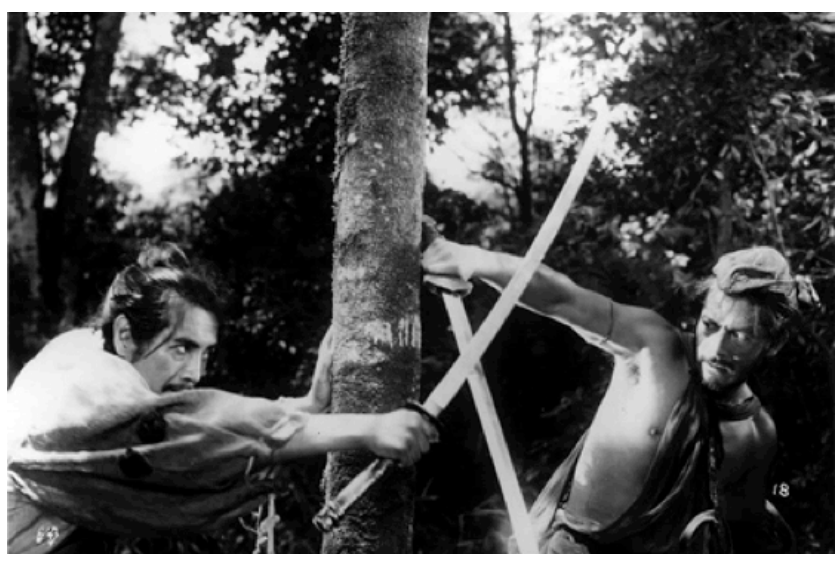

Por otra parte, Santiago Martín López Delacruz (Universidad de la República, Uruguay) analiza el documental camboyano La imagen perdida, que expone el genocidio ocurrido en Camboya entre 1975 y 1979. La problemática de la representación en el documental es uno de los ejes del artículo y de todo un conjunto de análisis que articula memoria y cine, que permite preguntarnos: ¿es posible representarlo todo? ¿Deberían existir ciertas "condiciones estéticas" para la representación de las dolorosas imágenes de crímenes de lesa humanidad? ¿Existe el género documental en tanto tal, separado completamente de la ficción? ¿Acaso el objetivo del documental es únicamente el constituirse como testimonio de lo vivido, o permite construir nuevas memorias? ¿Cómo se anudan las memorias personales y las colectivas?

En esta misma línea puede entenderse el artículo Fighting with films, de Josep Gavaldà Roca y Diego Mollá Furió (Universidad de Valencia, España), quienes analizan el discurso cinematográfico norteamericano en el período de la Primera Guerra Mundial, entendiendo que los límites entre el documental (o el género informativo) y la ficción son porosos, y que entonces el "valor propagandístico" puede hallarse en múltiples dispositivos y formatos.

En el artículo Evocación de memorias a través del cine de oro mexicano, Annika Maya Rivero y Maricruz Castro Ricalde (UNAM, México) proponen un interesante dispositivo clínico que radica en el uso del cine como herramienta de la terapia de reminiscencia en casos 
de demencia. En este dispositivo de intervención psicosocial se articulan, en acto, los recuerdos personales con los colectivos, ya que se trata de establecer un diálogo afectivo con lo que sucede en pantalla.

En La represión del deseo en el cine cubano: los antibéroes sexuales de Memorias del subdesarrollo, Cecilia y Fresa y Chocolate, Gabriel Guillén explora una interesante articulación entre la figura del playboy como antihéroe sexual y la censura cinematográfica cubana, destinada a prohibir imágenes sexuales en un proceso similar al de la censura norteamericana. Los tres filmes (que se realizaron en las décadas del 60, 80 y 90) enlazan el deseo sexual con la posibilidad social de expresarlo frente a otros, y más allá, de relatarlo cinematográficamente -demostrando que la represión, contención o condena cinematográfica de sus protagonistas representan la moral conservadora de la época.

En la misma línea, en el análisis del film argentino El hombre de al lado (2009), Ana Irene Medina y Mirta Carrasco proponen una lectura ética del conflicto entre vecinos del ya clásico film argentino, que puede verse como reflejo de su espacio y de su tiempo. La desidia frente al otro, las dificultades de la "ética de la convivencia”, y las dificultades de aceptación de lo diferente, son ejes centrales de un film que nos convoca en tanto representante de cierta cultura que va permaneciendo a lo largo de la historia, en una reverberación más o menos implícita de la extrema protección -o la desidia- de quienes miraban hacia un costado cuando se sucedía el terrorismo de Estado en Argentina.

Un efecto análogo de este minimalismo puede verse en Cine emergente en Ecuador: Poder y corrupción, de Álvaro Pazmiño Tello (Universidad Tecnológica Equinoccial, Ecuador), sobre el film El gobernador. En efecto, el autor señala allí que el film analizado se enmarca en un período de expansión del cine ecuatoriano que registra especialmente tópicos sociales, reflejando la realidad política en procesos de producción de escasa cantidad de días y con recursos limitados.
Valentín Huarte, de la Universidad Nacional de Córdoba, propone una original lectura sobre el clásico film 2001 Odisea en el espacio. A partir de hacer foco en la elipsis que propone Kubrick al inicio del film, suprimiendo un bloque espacio-temporal de cuatro millones de años (que acelera la unión entre el mono golpeando un hueso, y el hombre utilizando una herramienta en una nave espacial), Huarte propone leer esa continuidad en relación con la humanidad y la técnica, y reflexiona sobre el uso y la construcción de herramientas como condición para pensar en tradiciones y, por lo tanto, en memorias colectivas.

Cierran el número dos reseñas. La primera, sobre $E l$ ojo maravilloso. (Des)encuentros entre psicoanálisis y cine, último libro del psicoanalista Eduardo Laso, que propone un camino de articulación entre el interés del psicoanálisis por el cine, y el interés del cine por el psicoanálisis, con una rica compilación de la "cinemateca lacaniana” -películas mencionadas por Jacques Lacan en sus escritos y seminarios, comentados aquí con una nueva luz.

La segunda reseña propone una lectura sobre la serie TerraDois, de la televisión brasileña. Uno de los episodios, "Sinfonía sin fin", propone una situación que podría estar sucediendo en estos momentos: un músico manifiesta su deseo de "vivir para siempre" a través de la permanencia virtual en las redes sociales El anhelo de inmortalidad permite pensar los diferentes sentidos acerca de la identidad, la muerte, la finitud, y el lugar que pensamos que ocupamos en el Otro.

En su poema 1964, cuyo fragmento sirve de epígrafe a este editorial, Borges nos ofrece una imagen cinematográfica: se aproxima en cámara lenta a la imposible tarea de "aprender el arte del olvido". Y en sintonía, alejamos ahora la cámara con Marc Augé, quien asimila la memoria a un trabajo de escultura: "lo que queda no es un recuerdo simplemente, sino un recuerdo trabajado por el olvido".

\section{Referencias}

Augé, Marc (1998) Las formas del olvido. Barcelona: Editorial Gedisa.

Halbwachs, Maurice (2004). Los marcos sociales de la memoria. Barcelona: Anthropos.

Huyssen, Andreas (2000). En busca del futuro perdido. Cultura y memoria en tiempos de globalización. Buenos Aires: Fondo de Cultura Económica.

Jelin, Elizabeth (2002) (comp) Los trabajos de la memoria. Buenos Aires: Siglo XXI Editores.

Laso, Eduado (2016). La memoria de los verdugos. Memorias del VI Congreso Online de Ética y Cine. Facultad de Psicología, Universidad de Buenos Aires. Disponible en: http://www.eticaycine.org/Remember

Nora, Pierre (1992). Les Lieux de Mémoire. París: Gallimard. 